
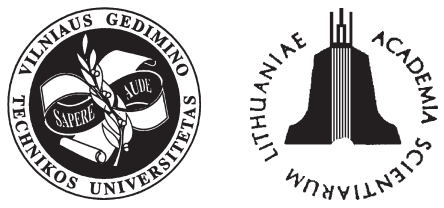

ISSN 1648-4142 TRANSPORT

http:/www.vtu.lt/english/editions

TRANSPORT-2005, Vol XX, No 3, 117-122

\title{
THE MAIN PRINCIPLES OF MODELLING THE INTERACTION BETWEEN TRANSPORT INFRASTRUCTURE DEVELOPMENT AND ECONOMY
}

\author{
Algirdas Jurkauskas', Diana Micevičiene் ${ }^{2}$, Jurgita Prunskiené $\dot{3}^{3}$ \\ Panevėžys Institute, Kaunas University of Technology, Klaipédos g. 1, LT-35209 Panevėžys, Lithuania \\ E-mail:19algirdas.jurkauskas@ktu.lt,2diana@midi.ppf.ktu.lt, ${ }^{3} d e k p p f @ k t u . l t$ \\ Received 2005-01-07; accepted 2005-03-25
}

\begin{abstract}
The practical need of measuring the interaction between transport infrastructure development and economic growth is determined by the neccesity to justify huge invetsments in infrastructure projects. As it was established the actuality of the topic analysed is proved by many authors working in the field. However, the main shortcoming in the presented work (stress only on the relationship transport infrastructure - economy expressed in the terms of additional production of GDP) is the existence of the playback between the interdependent items. Considering the practice to be cardinally inadequate in the terms of economic theory and modern attitude to ecological problems, the authors of the article present the main principles of quantitive evaluation of the aforementioned realationship taking into account overlaping links of the categories analysed.
\end{abstract}

Keywords: transport infrastructure, economic growth, GDP, interaction, mobility.

\section{Introduction}

The link between transport infrastructure and economic development has to play a significant role in the development of transport network plans in any country. In fact the relationship between investment in transport infrastructure and economic development has been the subject of investigation for quite little time. Despite this the subject remains mired in controversy. The discussion about the relationship between transport and economy arises as soon as one considers the exact significance of transport for economic development. The difficulty of establishing the relationship between transport and economy is that numerous other factors influence this relationship. Therefore, the process of economic development where other factors besides transport play a part, must have a central place in the consideration of transport and economy. Furthermore, most of studies do not take into consideration the playback between the elements analysed. So the aim of the paper was to determine the measurement principles of the interaction between transport and economy presenting the dependencies in the form of a model. Keeping in mind that the gross domestic product (GDP) is widely accepted as the most comprehensive measure of the size of economy, the object of the paper is considered to be the interdependence between transport infrastructure development and GDP growth. The aim pursued determined the methods of the research: systematic and logical analysis of scientific literature, analysis of the EU legal documents, mathematical modelling.

\section{The substantiation of modelling the interaction between transport and economy}

Keynes was one of the first to consider public work including investment in infrastructure for transport as a means to trigger economic development (Blaug, 1997). Keynes was especially concerned with the short period where the influence of investment on effective demand is essential and its significance for the capital stock may be neglected. This article will be focussed on the interaction between transport infrastructure development and economy in the long run in more empyrical context., for by now theory more than empirical evidence explains the renewed belief (especially in North America) that investments in transportation are capable of stimulating economic growth. (Ambe J. NJOH, 2000). The role of effectivelly functioning transport infrastructure as catalysator of GDP growth is considered to be of vital importance supporting Trans-European Transport networks - gigantic program of transport infrastruc- 
ture formation or modernization in the European Union. The question of connection between transport system (infrastructure appears to be an element of it) the development and economic potential was deeply discussed by Nakamuta in Japan. The liberal government in Canada also advocates susbtantial investments in public infrastructure as means of stimulating economic growth. Previous efforts to explore the relationship in developed countries at a time are presented by Costa, Ellson, \& Martin, 1991, Evans\&Karras, 1994, Garcia-Mila\&McGuire, 1992; Garcia-Mila, McGuire,\&Porter 1996 and others. So it is logical to state that the main infrastructure and economics reciprocity is a justification of investments in the transport sector.

Stipulated sequence of possitive effects in a territorial unit analysed appears from the close and overlaping connection between transport and economy.

\section{The influence of GDP growth on transport}

The economy or the value of GDP is one of the factors that influence the size and the type of transport. Traffic models reflect the influence of the economy by including regional product, regional income and/or employment as explanatory variables. These explanatory economic variables are exogenous (see for instance the New Regional Model of the Dutch Ministry of Transport, Public Works and Water Management, 1997). The same is found in equations for transport of passengers and goods in the $a c$ tivity-based approach in the framework of demand for transport (see for instance Meersman and Van de Voorde, 1991 and Meersman and Van de Voorde, 1997; see also Blauwens et al., 2002).

The disadvantage of this approach is that there is no feedback from transport to economy. Consequently, it does not allow one to estimate the extent to which the construction of new infrastructure or the improvement of existing infrastructure promotes economic development. Neither it is possible to determine to what extent not widening the infrastructure slows down the economic development (van de Vooren F. W. C. J., 2003).

\section{The influence of transport on the extent of GDP}

The above-mentioned disadvantage is eliminated, if the causal direction is reversed from transport to economy. An improvement of infrastructure implies lower transport costs, so that more (or longer) trips with the same quantity of labour, equipment and fuel are possible. More trips in business traffic and transport of goods lead to more production with the same quantities of input. More regional product leads in the second instance to more investment by which the growth of regional product increases.

In the framework of this view one can distinguish the following types of models:

- Production function models. The production function in these models contains, besides the usual production factors labour and capital, the production factor infrastructure as an explanatory variable for the national/regional product (see for instance Aschauer, 1989; Munnell, 1992; Gramlich, 1994; Gillen and Waters II, 1996; Gomez-Ibanez and Madrick, 1996; Rietveld and Bruinsma, 1998; Banister and Berechman, 2000).

- Location models. They explain investment or employment from a number of location factors, including infrastructure (Rietveld and Bruinsma, 1998). However, they neglect the influence of macroeconomic variables.

- General equilibrium models. They are comparative static models that specify the influence of transport and infrastructure on economy. They take into account agglomeration economies, economies to scale and market imperfections (see for instance Venables and Gasiorek, 1996; Knaap and Oosterhaven, 2001; and for the underlying theory Fujita et al., 1999).

In these models the causal relation from national/ regional product to transport and expenditures for improving infrastructure is neglected.

\section{Interaction between transport and economy}

The interaction between the measures presented by expanded Cobb-Douglas production to which the regional production structure and the regional urbanisation function are added. Because of lack of space the derivative dependences are not presented, keeping in mind that each variable of the formula is separately described:

$$
\begin{aligned}
& Y_{r}=A_{r} N_{r}^{\alpha} K_{r}^{\beta} \prod_{s=1}^{n} T p i_{s r}^{\gamma i} \prod_{s=1}^{n} T p i i_{s r}^{\gamma i i} \prod_{s=1}^{n} T p i i i i_{s r}^{\gamma i i i} \times \\
& \prod_{s=1}^{n} T p 1_{r s}^{\gamma 1} \prod_{s=1}^{n} T p 2_{r s}^{\gamma 2} \prod_{s=1}^{n} T p 3_{r s}^{\gamma^{3}} Q_{r}^{\delta} \exp \left(\varepsilon C_{r}\right),
\end{aligned}
$$

where:

$Y_{r}$ - real geographic product of region $\mathrm{r}$;

$A_{r}$ - state of technology in region $\mathrm{r} ; \mathrm{A}_{\mathrm{r}}$ is measured as a residue (see subsection $6.4 \mathrm{ad} \mathrm{e}$ );

$N_{r}$ - labour volume in region $\mathrm{r}$;

$K_{r}^{r}$ - real private stock of capital goods in region r; $T p i_{s r}$ - productive mobility of goods (number of tons) by lorry from region $\mathrm{s}$ to region $\mathrm{r}$;

$T p i i_{s r}$ - idem by train; 
Tpiii $_{s r}$ - idem by ship;

$T p 1_{r s}$ - productive mobility of business traffic (number of passengers) by car from region $r$ to region $s$ and back to the region of origin $r$;

$T p 2_{r s}$ - idem by train;

$T p 3_{r s}$ - idem by bus/tram/metro;

$Q_{r}-$ indicator for the production structure of region $\mathrm{r}$ : share of the labour-intensive industries in the real geographic product of the region; ${ }^{2}$

$C_{r}$-indicator for the extent of urbanisation of region r: share of the population of the municipalities with a head centre of more than 50,000 inhabitants in the total population of the region.

Input-output analysis can provide a means to model the interaction between transport and economy. To that end, a multiregional input-output model is necessary where the intersectoral flows have a spatial dimension in the form of transport costs (van de Vooren F. W. C. J, 2003).

The intersectoral value flows of commodities are transformed in transport flows. Changes in transport cost result in changes of economy. Changes in economy result in changes of transport flows.

Input-output analysis is subjected to restrictive assumptions with regard to the technical relationships between industries. It ignores the existence of supply constraints. A practical problem is the high cost of collecting the data. Furthermore, the model takes into account only transport of goods. Finally, the model cannot simulate a process of economic growth in connection with transport.

In this article the relationship between transport and economy will be elaborated in the form of a dynamic, interregional model about economy, transport, infrastructure and other regional features named MOBILEC (MOBILity/EConomy) presented by van de Vooren F. W. C. J. exposing the main shortcomings and inadequacies that do not allow to treat the model as fully meeting modern requirements and principles of global sustainable development.

\section{A non-formal approach of the model MOBILEC}

The infrastructure utilized is identified with the mobility for productive ends expressed in the terms of the number of passengers and the number of tons of goods that have been moved through this infrastructure. Transport of goods and business traffic relate to productive mobility (expressed in the number of tons or passengers between two points in space). If the moving motive refers to shopping, attending of education courses, paying of visits/staying, recreation/ sport and driving/walking, it is a matter of consumptive mobility (expressed in the number of passengers between two points in space). The nature of commuter traffic is more complicated to establish. Commuter traffic is the consequence of a productive performance outside the residence; for this reason it is a matter of productive mobility. On the other hand, it can be assumed that commuter traffic is the consequence of the consumptive wish of living in more attractive environment than the one is working; in this view commuter traffic should be counted as consumptive mobility.

The production function contains productive mobility and not consumptive mobility. In accordance with the production function, the direction of the causal connection goes from mobility to economy. In the case of consumptive mobility the consumption function which describes the relation between income and consumption plays a part. In accordance with the consumption function the direction of the causal connection goes from economy to mobility.

Infrastructure is a limiting condition-to change by policy-for the total of productive and consumptive mobility and therefore for the economic development. Before the maximum mobility is reached, the limiting effect of infrastructure is revealed in the form of increased travel time and mobility price. The mobility price is defined as generalized transport costs per passenger or per ton (freight transport). It consists of two parts: travel-distance costs (or distance price of mobility) and travel-time costs; travel-time costs are the result of monetary evaluation of travel time (see for instance the Dutch Ministry of Transport, Public Works and Water Management, 1996). The smaller the difference between the actual mobility and the maximum possible mobility (capacity of infrastructure), the lower is the velocity of transport and the greater the travel-time costs. The type of infrastructure imposes restrictions on the means of transport and its velocity. These restrictions, too, are expressed in the mobility price (van de Vooren F. W. C. J, 2003).

The model makes use of matrices of origin-destination where the quality of accessibility within and between regions is expressed in the terms of travel distance, travel time, travel-distance costs and traveltime costs, on the basis of a network of infrastructure. The model cannot assign the flows of transport to specific stretches of infrastructure. It generates the flows of transport within a region and between pairs of regions. It takes into account that the infrastructure of a region is utilized by transit traffic between other regions.

Infrastructure is one of the factors that characterize regions. We take up the approach of location models by introducing other regional features in the model, for example technological development, regional production structure, urbanisation (agglomeration economies and diseconomies), level of wage rate, 
existence of recreation areas, size of the population related to the area and the employment, investment premiums and geographic position. Their influence on economy and mobility is also taken into consideration.

The model is interregional because regions affect each other. The interaction is caused not only by interregional flows of transport, but also by private investment. The amount of money saved in a certain region can be used as investment in another region if the capital rate of return is higher in that region, (van de Vooren F. W. C. J, 2003). The regional income in period $t$ determines regional (private) saving in pe$\operatorname{riod} t$, which-dependent on the balance of government spending in the region and taxes levied in the region and on the balance of payments of the region - is used as (private) investment. To what extent saving is used as investment in the own region or elsewhere, depends on the capital rate of return $r$ in relation to that in other regions. Regional (private) investment is just an extension of the (private) stock of capital goods; so the region disposes of a larger stock of capital goods at the beginning of the next period $t+1$ than at the beginning of period $t$.

Neoclassical theory teaches that the marginal labour productivity determines the real wage rate w. This relation is reversed in MOBILEC. The real wage rate agreed by employers and employees, is considered as an exogenous variable. It determines the marginal labour productivity. The real price of productive mobility determines the marginal mobility produictivity, simultaneously the regional product, the employment and the productive mobility in period $t+1$. The state of technology, the regional structure of production and the degree of urbanisation in period $t+1$ are exogenous. The regional product accrues to the population in the form of regional income which influences the consumptive mobility (and the commuter traffic) in period $t+1$. The consumptive mobility also depends on the distance-price of consumptive mobility and travel time as well as the metropolitan character and the existence of recreation areas in the own region in relation to the other regions.

From this point the process starts again: the regional income determines regional saving in period $t+1$ which is used as investment in the own region or elsewhere, etc. Thus the model simulates a continuous process of the development of economy and mobility. Travel time and mobility prices rise as a result of increasing utilization of the disposable infrastructure what has a negative influence on the growth of economy and mobility.

This system of relations produces, as most important output, time paths of the following variables:

\& regional/national product, employment and investment by region;

$\Leftrightarrow$ ransportation of goods by lorry, train and ship (productive mobility) within a region and between regions;

\$ transporation of passengers by car, train and bus/ tram/metro within a region and between regions, split up into business traffic (productive mobility), commuter traffic and other traffic (consumptive mobility) (van de Vooren F., W., C., 2003).

\section{The preconditions for correction of MOBILEC: essential accents}

It was already mentioned that GDP is widely accepted as the most comprehensive measure of the size of economy. Transport sector is considered to be a component of economy, naturally it is often measured against GDP. The problem is that the relationship is a multi-faced one and measures of transportation in relation to GDP are not always based on a conceptual framework that explicitly reflects the unellying relationship (Fang \& Han, 2000). So the first problem is that despite the fact that the model described above depicts the distinct algorythm of measurment the relationship between the mentioned dependences emphasizing the playback between them, the essential facets of both GDP and changes in transportation demand or suply stipulated by the improvement of transport infrastructure are not taken into consideration. GDP and transportation services are measured on a demand and supply side. GDP as a measure of production represents the final results of the production activities of resident producer units - sum of gross valued added. From the demand perspective GDP is equal to the sum of the final users measured in purchasers prices. The supply side of transportation services that are privided thanks to developed infrasructure is often designated as transporation industry. The demand side of transportation is the use of goods and services for transportation purposes (Fang \& Han, 2000). Fig 1 provides a simple reprsentation of the relationship between GDP and transportation.

It is wise to state that the improved transport infrastructure affects and stipulates the development of transport on both demand and supply perspectives, but the model defined in part 6 does not explain if the presumption is correct. Furthermore, it is not clear if the author explores the effects of infrastructure development on regional GDP as a total value added or final demand indicator and vice versa. In this case the terms of "productive mobility" and "compsumptive mobility" as the main impulses of economic growth should be concretized attributing their causal ad- 
equacy as a stipulating GDP factor. The shortcoming for the sake of scientific transparency should be eliminated in the suggested way. Firtsly, GDP consists of two main elements that are influenced by increased mobility which stipulated transport infrastructure improvement. The concept of productive mobility should be attributed to the category of transport operators described in Fig 1 because it represents the volume of transport flows due to any business (both production and services). The concept of consumption mobility is delegated to the category of total demand of transportation because having a possibility to travel on consumptive perspective, the households need transport infrastructure, servces and means and form additional transport demand. Secondly, it is necessary to separate GDP elements speaking about the interaction between economy and transport infrastructure. Productive mobility increased determines GDP growth in the terms of both value added and final demand positions.

Though as Figure 1 shows, the consumptive mobility is influenced by GDP as the final demand only.

The second problem noticed is the ignorance of environemental problems due to trans.port infrastructure development and economic growth. Modern economy (transport sector is a part of it) should be managed by principles of sustainability. Sustainability is defined as possibility for the members of any society to satisfy their economic, social and ergonomic needs and improve their quality of life. Pollution,

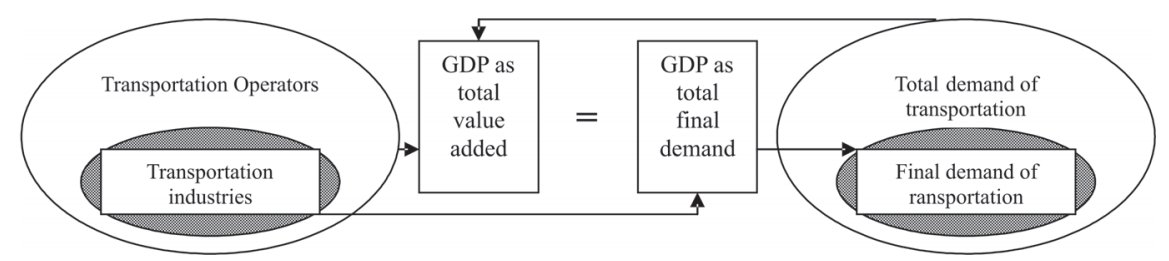

Fig 1. Transportation in relation to GDP

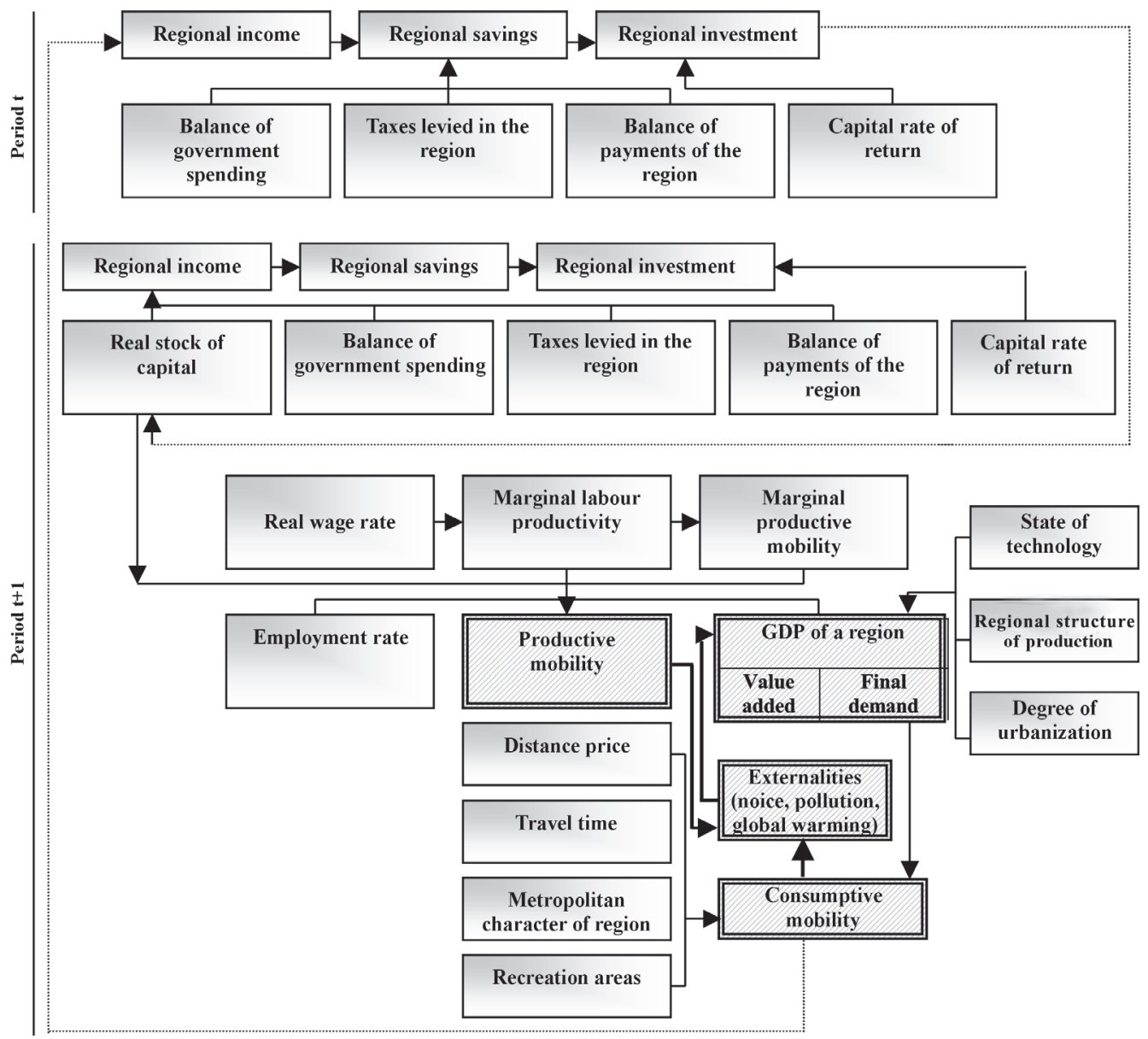

Fig 2. Model of transport interaction with economy 
noise, global warming, inadequate use of resources, physical and mental weariness directly influencing the members of society contribute to the world's economic evolution and impede GDP growth. So the externalities mentioned must necessarily be taken into consideration as a harmful consequence of the mentioned relationship between the two categories analysed.

Finally it is rather important to notice that the measurment of positive and negative effects of interaction between transport infrastructure development and GDP growth depicts the real and overall impact of the mentioned dependences and allows to determine the losses or gains arrising. The changed and corrected model (corrections are shown in a different color of the blocks) according the stated remarks is presented in Fig 2.

\section{Conclusions}

In conclusion, the contribution of the problem discussed in the article is a new approach to the interaction between transport and economy. Despite the fact that the main precondition of the scientific analysis presented was the need of an instrument to substantiate huge sums of money invested in the transport infrastructure, it was determined that the interaction between economy growth and transportation system development must be explored in a more accurate, complex way as the subjects appear to have a multiplex character. The concepts of sustainable growth both in economy and transport sector must be analysed in the terms of sustainability.

\section{References}

1. Ambe J. NJOH. Transportation infrastructure and economic development in sub-Saharan Africo. Pubilc works management \& Policy, Vol 4, April 2000, p. 286-296.

2. Aschauer, A. D. Is Public Expenditure Productive? The Journal of Monetary Economics, 1989, p. 177-200.

3. Aschaeur, D. A. Why is infrastructure important? In: A. H. Munnell (Ed.) Is there a shortfall in public capital investment? Boston: Federal Reserve Bank of Boston, 1990, p. 21-50.
4. Blaug, M. Economic Theory in Retrospect, Cambridge University Press, 1997, p. 644, 645, 648, 649 and 663.

5. Costa, J. S.; Ellson, R. W.; \& Martin, R. C. Public capital, regional output, and development: Some empirical evidence. Journal of Regional Science, 27(2), 1987, p. 419-437.

6. Duffy-Deno, K. T.; \& Eberts, R. W. Public infrastructure and regional economic development: A simultaneous equations approach. Journal of Urban Economics, 1991, 30(3), p. 329-343.

7. Evans, P.; \& Karras, G. Is government capital productive? Evidence from a panel of seven countries. Journal of Macroeconomics, 16(2), 1994, p. 271-279.

8. Fang, B.; Han, X. Relating Transportation to GDP: Concepts, Measures and Dala. Washington, 2000.

9. Fogel, R. W. Railroads and American Economic Growth; Essays in Econometric History, Johns Hopkins University Press, Baltimore, 1964.

10. Forkenbrock, D. J.; \& Foster, N. Economic benefits of corridor highway investment. Transportation Research A, 24A(4), 1990, p. 302-312.

11. Garcia-Milà, T. \& T. McGuire. The Contribution of Public Provided inputs to State's Economies. Regional Science and Urban Economics, 1992, p. 229-242.

12. Garcia-Mila, T.; McGuire, J.; \& Porter, R. II. The effect of public capital in state-level production functions reconsidered. Review of Economics and Statistics, 1996, 75(1), p. 177-180.

13. Gillen, D. W.; \& W. G. Waters II, eds. Transport Infrastructure Investment and Economic Development. The Logistics and Transportation Review, Vol 32, No 1, 1996.

14. Hunter, H. Transport in Soviet and Chinese Development. Economic Development and Cultural Change, 1965, p. 71-72.

15. Van der Waard, J. Concept Handboek Elasticiteiten, Adviesdienst Verkeer en Vervoer (Ministry of Transport, Public Works and Water Management), Rotterdam, 1990.

16. Van de Vooren, F. W. C. J. Toward Welfare Optimal Planning of Infrastructure. In: Networks for Mobility, International Symposium, University of Stuttgart, Stuttgart, 2002, p. 146-156.

17. Van de Vooren, F. W. C. J. Modelling transport in interaction with economy. Transportation Research, part E, 2004 published online via Science Direct in June 2004. 